\title{
WEIGHTED APPROXIMATION BY BASKAKOV OPERATORS
}

\author{
IVAN GADJEV
}

Abstract. The weighted approximation errors of Baskakov operator is characterized for weights of the form $w(x)=x^{\gamma_{0}}(1+x)^{\gamma_{\infty}}$, where $\gamma_{0} \in[-1,0], \gamma_{\infty} \in \mathbb{R}$. Direct inequalities and strong converse inequalities of type A are proved in terms of the weighted $K$-functional.

Mathematics subject classification (2010): 41A36, 41A25, 41A27, 41A17.

Keywords and phrases: Baskakov operator, $K$-functional, direct theorem, strong converse theorem.

\section{REFERENCES}

[1] N. T. Amanov, On the weighted approximation by Szász-Mirakjan operators, Anal. Math, 18, (1992), $167-184$.

[2] V. A. BASKAKOV, An instance of a sequence of the linear positive operators in the space of continuous functions, Docl. Akad. Nauk SSSR, 113, (1957), 249-251.

[3] M. BECKER, Global approximation theorems for Szász-Mirakjan and Baskakov operators in polynomial weght spaces, Indiana Univ. Math. J., 1 27, (1978), 127-142.

[4] Z. DitZiAn, A global inverse theorem for combinations of Bernstein polynomials, J. Approx. Theory, 26, (1979), 277-292.

[5] Z. DitZian, Direct estimate for Bernstein polynomials, J. Approx. Theory, 79, (1994), 165-166.

[6] Z. Ditzian, Rate convergence for Bernstein polynomials revisited, J. Approx. Theory, 50, (1987), $40-48$.

[7] Z. Ditzian And K. G. Ivanov, Strong converse inequalities, J. Anal. Math., 61, (1993), 61-111.

[8] Z. Ditzian AND V. Totik, Moduli of Smoothness, Springer, Berlin, New York, 1987.

[9] B. R. DRAGanov AND K. G. Ivanov, Natural weights for uniform approximation by the SzászMirakjan operator, Constructive Theory of Functions, Sozopol 2013, (2014), 1-27.

[10] M. Felten, Direct and inverse estimates for Bernstein polynomials, Constr. Approx., 14, (1998), $459-468$.

[11] M. FeLten, Local and global approximation theorems for positive linear operators, J. Approx. Theory, 94, (1998), 396-419.

[12] Guo FEnG, Direct and inverse approximation theorems for Baskakov operators with the Jacobi-Type weights, Abstract and Applied Analysis, Volume 2011, (2011).

[13] Z. FinTA, On converse approximation theorems, J. Math. Anal. Appl., 312, (2005), 159-180.

[14] I. GADJEV, Strong converse result for Baskakov operator, Serdica Math. Journal, 40, (2014), 273-318.

[15] Sh. Guo And Q. QI, Strong converse inequalities for Baskakov operators, J. Approx. Theory, 124, (2003), 219-231.

[16] A. HolHoş, Uniform weighted approximation by positive linear operators, Stud. Univ. Babes-Bolyai Math, 56 No. 3, (2011), 135-146.

[17] K. G. IVANov, Natural weights for uniform approximation by Bernstein polynomials, manuscript, (2011).

[18] Hans-Bernd KNOOP AND XIN-LONG Zhou, The lower estimate for linear positive operators (II), Results in Mathematics, 25, (1994), 316-330.

[19] G. Lorentz, Bernstein Polynomials, Mathematical Expositions, Univ. of Toronto Press 8, 1953.

[20] V. TотіK, Approximation by Bernstein polynomials, Amer. J. Math., 116, (1994), 995-1018.

[21] E. V. WICKEREN, Stechkin-Marchaud-type inequalities in connection with Bernstein polynomials, Constr. Approx., 2, (1986), 331-337. 
[22] P. C. XUN AND D. X. ZHOU, Rate of convergence for Baskakov operators with Jacobi-weights, Acta Mathematics Applicatae Sinica, 18, (1995), 127-139.

[23] Ding-Xuan Zhou, On a conjecture of Z. Ditzian, J. Approx. Theory, 69, (1992), 167-172. 